\title{
Microstructural Characterization of Industrial Chromite and Spinel Cement Kiln Refractories with Emphasis on the Iron-rich Rims
}

\author{
Y. Mercanköşk ${ }^{1}$, S. Akkurt ${ }^{2}$ and M. Çiftçioğlu ${ }^{3}$ \\ ${ }^{1}$ Çimentaş Cement Co. Işıkkent, İzmir 35050 Turkey \\ ${ }^{2}$ Mechanical Engineering Department, İzmir Institute of Technology, İzmir, 35437, Turkey \\ ${ }^{3}$ Chemical Engineering Department, İzmir Institute of Technology, İzmir, 35437, Turkey
}

Keywords: Chromite, spinel, refractory, microstructure, iron-rich rim.

\begin{abstract}
Magnesia-chromite $\left(\mathrm{MgO}+\mathrm{MgO} \cdot \mathrm{Cr}_{2} \mathrm{O}_{3}\right)$ and magnesia-spinel $\left(\mathrm{MgO}+\mathrm{MgO} \cdot \mathrm{Al}_{2} \mathrm{O}_{3}\right)$ refractory bricks that are used in the high temperature zones of rotary cement kilns are investigated for their microstructural characteristics. Their microstructures are important because the size, shape and distribution of periclase grains, chromites and the quality of their bonding phases significantly affect their service performances. The purpose of this study was to characterize the microstructures of industrial brick samples to develop a protocol to compare different products e.g. for evaluation as replacement bricks. In some of the chromite containing bricks iron-rich rims were observed, while a domestic brick with similar chemistry had no such feature. These iron-rich rims were examined using SEM-EDS. It was found that the counter-diffusion of $\mathrm{Fe}^{+3}$ and $\mathrm{Cr}^{+3}$ were responsible for their formation. Exsolved chrome-spinel was widely observed in the microstructures of chromite bricks. Magnesia-spinel bricks were found to contain low melting calcium aluminates as bond phases in the microstructure, posing a threat to service performance. Portmortem microanalysis of industrially used bricks revealed alkali attack in addition to creep as main destruction mechanisms for brick. Traces of elements like Mo, S and alkalies were observed and thought to originate from the use of waste derived fuels.
\end{abstract}

\section{Introduction}

Refractory materials like magnesia-chromite $\left(\mathrm{MgO}+\mathrm{MgO} \cdot \mathrm{Cr}_{2} \mathrm{O}_{3}\right)$, magnesia-spinel $(\mathrm{MgO}+$ $\left.\mathrm{MgO} \cdot \mathrm{Al}_{2} \mathrm{O}_{3}\right)$, dolomite $(\mathrm{MgO}+\mathrm{CaO})$ and bricks with zirconia $\left(\mathrm{ZrO}_{2}\right)$ additions are used for lining the hot zones of cement kilns [1]. Recently, due to environmental pressure, the traditional magnesiachromites are replaced by the more environment friendly magnesia-spinel and dolomite bricks in the transition and sintering zones of the kiln $[2,3]$. This transtion is partially complete in the developing world but totally accomplished in the industrialized countries.

To compare different products for evaluation as replacement bricks and to minimize refractory wear, an understanding of the underlying chemical mechanisms must be developed. The way in which the different phases are assembled in the microstructure significantly determines the resulting corrosion behavior [4]. Refractories are generally composed of large filler grains of high melting point and a smaller grained second phase to impart high temperature bonding and packing [5]. High-melting bond phases between the refractory grains are favorable while low melting phases with a high degree of wetting are avoided when possible. Fortunately in industrial practice the hot faces of cement kiln refractories are coated with a partially solidifed cement clinker melt that acts as a protective coating like an in-situ refractory. This is a favorable condition that reduces total wear. The corrosion of these refractories were investigated in a number of studies [6-9]. The iron rich rim formation and the resulting microstructures were, however, not much reported except the works of 
Kohn et.al., who claimed that their formation occurs via counterdiffusion of $\mathrm{Fe}^{+3}$ and $\mathrm{Cr}^{+3}$ ions at high temperatures $[10,11]$.

In this study, the microstructures of unused and used cement kiln refractories of different types are investigated. The purpose was to understand and to compare the corrosion potentials of different types of bricks by investigating their microstructures. Iron-rich rims were specifically investigated.

\section{Materials and Method}

Brick Samples. The types of bricks examined in this study were magnesia-chromite and magnesia spinel made by three different manufacturers, one local (brick C) and two imported (bricks A and B). Selected published properties of these bricks are given in Table 1. Analysis of commercial chromites are also given for comparison purposes.

Table 1. Published chemical analysis of different types of commercially available chromites and the grains observed in this study.

\begin{tabular}{|c|c|c|c|c|c|c|c|c|c|c|c|}
\hline & \multirow{2}{*}{ 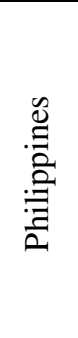 } & \multirow{2}{*}{ 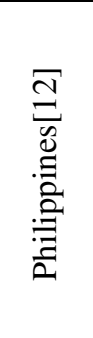 } & \multirow{2}{*}{ 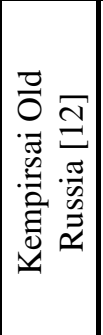 } & \multirow{2}{*}{ 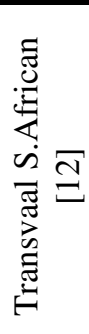 } & \multirow{2}{*}{ 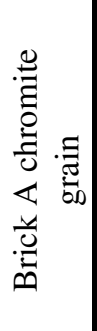 } & \multirow{2}{*}{ 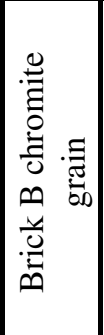 } & \multirow{2}{*}{ 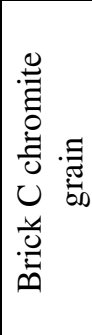 } & \multicolumn{4}{|c|}{$\begin{array}{l}\text { EDS analysis performed in this study } \\
\text { for the chromite grain and the rim } \\
\text { area in brick B. }\end{array}$} \\
\hline & & & & & & & & 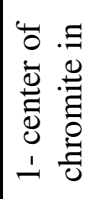 & 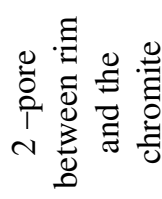 & 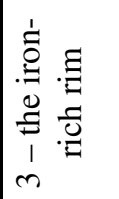 & 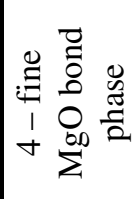 \\
\hline $\mathrm{MgO}$ & 17.9 & 18.06 & 14.92 & 10.1 & 21.51 & 21.2 & 19.8 & 21.15 & 10.44 & 22.46 & 86.93 \\
\hline $\mathrm{Al}_{2} \mathrm{O}_{3}$ & 29.6 & 30.2 & 9.92 & 15.5 & 15.6 & 16.2 & 14.2 & 16.16 & 13.82 & 13.45 & 1.79 \\
\hline $\mathrm{SiO}_{2}$ & 5 & 5 & 5.02 & 2.24 & 0.52 & 0.6 & 1.24 & 0.55 & 1.67 & 0.74 & 0.50 \\
\hline $\mathrm{CaO}$ & 0.2 & - & - & - & 1.35 & 1.3 & 1.17 & 1.34 & 7.71 & 1.29 & 0.22 \\
\hline $\mathrm{Cr}_{2} \mathrm{O}_{3}$ & 33.7 & 32.1 & 54.91 & 44.52 & 51.72 & 46.4 & 45.7 & 46.40 & 23.29 & 24.62 & 3.32 \\
\hline $\mathrm{MnO}$ & - & - & - & - & - & 0.57 & & 0.57 & 1.05 & 0.60 & 0.36 \\
\hline $\mathrm{Fe}_{2} \mathrm{O}_{3}$ & 14.6 & 14.14 & 13.79 & 27.47 & 9.29 & 13.8 & \begin{tabular}{|l|}
17.8 \\
\end{tabular} & 13.83 & 42.03 & 36.84 & 6.89 \\
\hline Total & 101 & 99.5 & & 99.83 & 99.99 & $\begin{array}{c}100.0 \\
7\end{array}$ & 99.91 & 100 & 100 & 100 & 100 \\
\hline
\end{tabular}

Microscopy. An optical reflected light microscope (Nikon L150) and a scanning electron microscope (Philips XL30 SFEG SEM) coupled with EDS (Energy dispersive x-ray microanalysis system EDAX) were used for microanalysis. Backscattered electron imaging (BSE) was primarily used for SEM examination of polished specimens due to the ability to separate different phases based on the atomic number contrasts [4]. The EDS analysis for each element or oxide was also performed to track the semi-quantitative compositional changes along the cross section of the samples. All samples were as polished without etching, and were gold-coated to avoid charging.

\section{Results and Discussion}

Optical and Electron Microscopy. General microstructural features of samples A to C were as follows: Plane polarized light showed the presence of large periclase grains $(500-2000 \mu \mathrm{m})$ and moderately sized chromites $(50-500 \mu \mathrm{m})$ distributed uniformly in a fine sized $(<1-50 \mu \mathrm{m})$ magnesia bonding matrix phase (Figure 1a). A similar microstructure was observed for brick D except for spinel grains instead of chromites. Brick A contained rounded chromite grains with an iron-rich rim that was covering the whole perimeter of each grain (Figure 1a, 1b and 2a). These grains were 
strongly bright in plane-polarized light (PP) and dark blue in cross polars (CP) because chromite gives high order colors on extinction [13]. The rim was about 10-20 $\mu \mathrm{m}$ away from the edge of the chromite grains and was on the average $10 \mu \mathrm{m}$ thick. Brick C contained relatively larger (600$800 \mu \mathrm{m})$ and geometric shaped chromite grains with the same dark blue extinction color on $\mathrm{CP}$ image. These grains in brick $\mathrm{C}$ did not have the rims that were observed in bricks $\mathrm{A}$ and $\mathrm{B}$, suggesting a different processing method. Gaps were observed at the periphery of the chromite grains. Periclase grain size for brick A was smaller than that for brick $\mathrm{C}$, resulting in a better dispersion in the microstructure. Exsolved spinel was widely observed within the periclase grains but the grain boundary phases of periclase grains will not be reported here for the sake of brevity. Such studies can be found in references 4-6.

The Iron-Rich Rims. Figures $1 \mathrm{~b}$ and $2 \mathrm{a}$ show the chromite grains with iron rich rims in the unused brick. Selected spots along a line extending from the center area to the rim are numbered 1-4 in Figure 2a. EDS analysis of these spots are given in Table 1. The Fe concentration increases from the center of the chromite $(13.8 \%)$ to the rim $(36.8 \%)$, and decreases again in the matrix magnesia phase $(6.89 \%)$. Cr concentration, on the other hand, significantly decreases along the same path (12-3-4). The porous region (Figure 2a, \#2) was relatively richer in $\mathrm{CaO}$ and Fe-oxide.

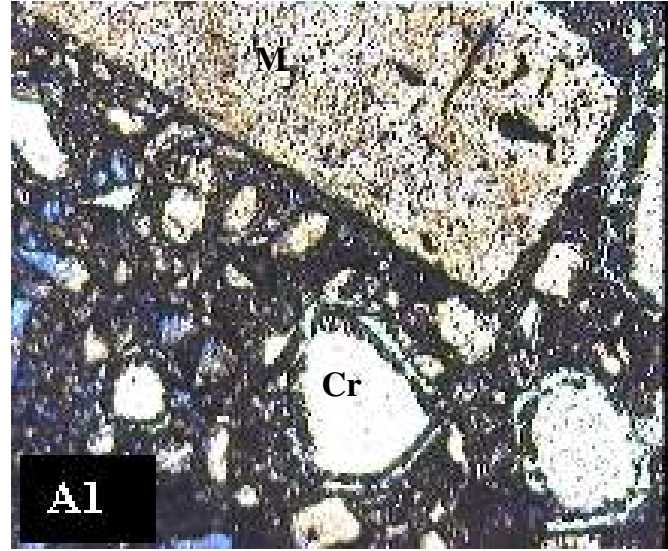

(a)

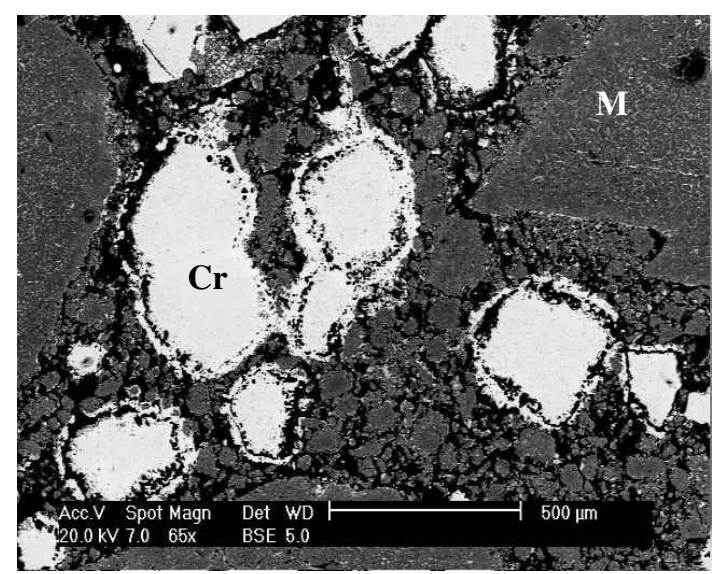

(b)

Figure 1. Micrographs of brick A. (a) Cross polars optical microscope image (A1), (b)SEM BSE image. M: magnesia grain, Cr:chromite grain.

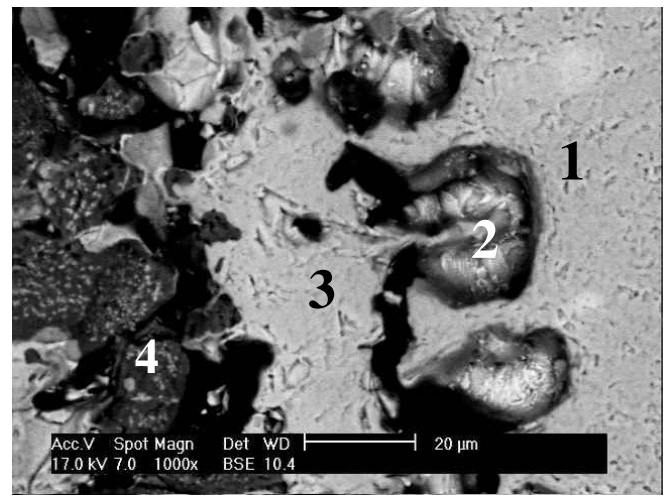

(a)

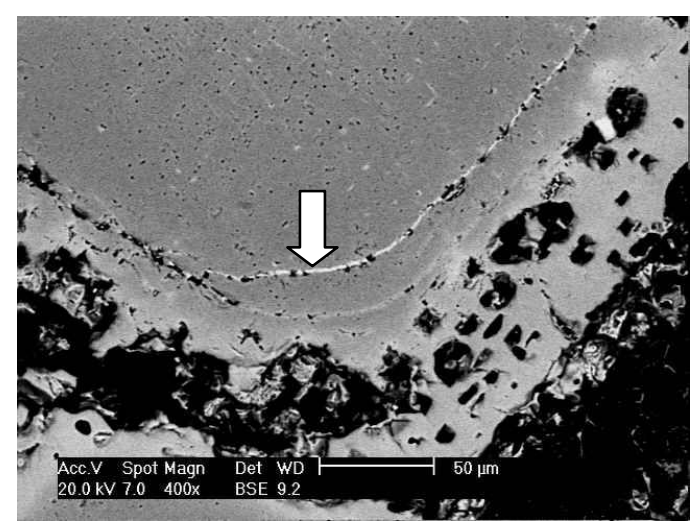

(b)

Figure 2. SEM images (BSE) of (a) unused brick A, and (b) Industrially used brick B. Notice the Ca-rich front shown by the arrow in (b). 
Kohn reported that iron-rich rim forms due to the diffusion of $\mathrm{Fe}^{+3}$ from periclase out to the spinel (chromite) which supplies $\mathrm{Cr}^{+3}$. He further claims that the rims disappear on extended heating (39hrs) at $1530^{\circ} \mathrm{C} \mathrm{[11].} \mathrm{Our} \mathrm{results,} \mathrm{however,} \mathrm{showed} \mathrm{that} \mathrm{bricks} \mathrm{used} \mathrm{at} \mathrm{T} 1450^{\circ} \mathrm{C}$ for 8 months still contained the rims (Figure $2 \mathrm{~b}$ ). Important microstructural features of the used bricks revealed that there were multiple calcia rich fronts within the chromite grains parallel to the periphery (shown by arrow). Cracks were also observed parallel to the surface of the chromite grains. They may potentially result from thermal expansion mismatch although other creep cracks during extended high temperature service were also found. These cracks were analyzed to contain $\mathrm{S}, \mathrm{Na}$ and $\mathrm{K}(8.3 \%)$. Isolated pockets in the porous rim region rich in $\mathrm{Mn}(<1 \%), \mathrm{V}, \mathrm{Zn}, \mathrm{K}$ (up to $32 \%$ ) and S (up to $3 \%$ ) were detected by EDS analysis. These findings suggested that WDF (waste derived fuel) was used in the rotary cement kiln.

\section{Conclusions}

Microstructural analysis of industrial chromite and spinel bricks revealed the general microstructural characteristics. Iron-rich rims, large periclase crystals, smaller chromite grains all embedded in a fine magnesia matrix were the general microstructures of magnesia-chromite bricks. Magnesia spinel bricks were found to have a similar microstructure except for the replacement of chromite with spinel. Iron-rich rims were analyzed by EDS for their elemental compositions and counterdiffusion of $\mathrm{Fe}$ and $\mathrm{Cr}$ are thought to be responsible for their formation. Used bricks had large peripheral cracks inside the chromite grains filled with alkalies and sulfur. Other chromite grains had multiple $\mathrm{Ca}$ rich fronts running parallel to the surface. WDF effects were observed in isolated pockets in the chromites in the form of excessive amounts of alkalies and $\mathrm{S}$.

\section{References}

[1] P. Bartha and H.J. Klischat: CN-Refractories Vol. 6, No:3 (1999) p.31-38.

[2] D.J. Griffin: World Cement, March (1996) p.88-92.

[3] J.Klischat: Proceedings of Unified International Technical Conference on Refractories, UNITECR, Cancun, Mexico, (2001).

[4] K. Goto and W.E. Lee: J.Amer.Cer.Soc. Vol.78 No:7 (1995), p. 1753-1760.

[5] W.E.Lee: Comprehensive composite materials, Vol:4 Carbon-Carbon, cement and ceramic matrix composites (Pergamon Press, New York 2000), p.363-385.

[6] Y.Mercankosk, Master's Thesis, Fall 2002, Izmir Institute of Technology, Turkey.

[7] M. Olbrich: Zement Kalk Gips Vol. 9 (1991), p. 478-482.

[8] Z. Qotaibi et.al.: Ann.Chim.Sci.Mat. Vol.23 (1998), p.169-172.

[9] P.T.Jones, et.al.: J.Eu.Cer.Soc. Vol. 22 (2002), p. 903-916.

[10] S.C.Kohn and B.C.M.Butler: Br.Cer.Trans.J. Vol.84 (1985) p.15-18.

[11] S.C.Kohn: Materials Science Forum Vol.7 (1986) p.133-138.

[12] D.A. Brosnan: Private Communication, (2002).

[13] W.D. Nesse: Introduction to Optical mineralogy (Oxford University Press, Oxford 1991). 


\section{Euro Ceramics VIII}

10.4028/www.scientific.net/KEM.264-268

Microstructural Characterization of Industrial Chromite and Spinel Cement Kiln Refractories with Emphasis on the Iron-Rich Rims

10.4028/www.scientific.net/KEM.264-268.1763

\section{DOI References}

[8] Z. Qotaibi et.al.: Ann.Chim.Sci.Mat. Vol.23 (1998), p.169-172.

10.1016/S0151-9107(98)80048-2 